\title{
SUSTAINABLE DESIGN THINKING AND SOCIAL INNOVATION FOR BEATING BARRIERS TO CIRCULAR ECONOMY
}

\author{
DENIZ DENIZ \\ Faculty of Fine Arts and Design, Izmir University of Economics, Turkey
}

\begin{abstract}
Circular economy is a complex context through the viewpoint of sustainability, design thinking and innovation with environmental, economic, and social dimensions. In this respect, circular economy is part of the crucial components for sustainable development by transforming the culture through design thinking and social innovation whether imposed from the top or initiated at the bottom. According to the sustainable design thinking approach, achieving successful solutions for innovation depends on understanding the barriers and trying to remove them as much as possible. Circular economy and social innovation mainly try to integrate economic activity with environmental, social, and physical well-being by bringing out ideas for transition of cities. In this respect, design is at the heart of circular economy which helps to close resource loops to from linear to circular by integrating circular economy concerns earlier in the design process for sustainable and long-term solutions. This paper mainly considers the theoretical framework and focuses on the circular economy regarding sustainable design thinking and social innovation. In addition, a workshop conducted to bring decision-makers, designers and stakeholders together to focus on how to create a new way of thinking for beating barriers through circular design. The discussions and results of the workshop also presented to help to create sustainable solutions for cities.

Keywords: circular economy, sustainability, sustainable design thinking, social innovation.
\end{abstract}

\section{INTRODUCTION}

Circular economy is one of the three pillars of sustainability where transforming the culture through sustainable design thinking and social innovation are crucial for this process. It has a vital role to play for sustainable development of cities whether imposed from the top or initiated at the bottom. Circular economy has a complex context of solution through the viewpoint of sustainability, design thinking and innovation with a perspective built on environmental, economic, and social dimensions. It is a greater way of handling the obstacles and producing solutions with an interdisciplinary approach. In this respect, design is at the heart of circular economy which creates resource loops to move from a linear one to a circular.

Circular economy mainly tries to integrate economic activity with environmental and social well-being by creating new ideas for transition of cities and to create space for bringing issues and related actors together in practice and theory. The circular economy concept emerges from 1985 onward and it has roots in environmental economics [1] where the evolution in environmental awareness derived from this concept. Circular economy is about sustainable development no matter how it was initiated from the top or at the bottom. In this respect, design has a huge impact on circular economy in many aspects considering the whole process. As suggested by Bocken et al. [2] a list of design strategies exist to close resource loops to move from a linear to a circular economy where they are integrated earlier in the design process. Ellen MacArthur Foundation [3] emphasizes that circular economy mainly defined as an industrial system, which considers the end-of-life concept through the use of renewable energy and finally aims for zero waste through design. Prendeville et al. [4] focuses on circular cities and state that although the governments and policymakers 
were willing to include circular economy in their duties, they were not clear about the meaning of a circular city when it comes to practice.

The circular city is mainly defined as a city that implements circular economy principles collaborating with urban stakeholders where design can play an important role to develop environmentally friendly products and services of the city like buildings, infrastructure, and landfills [5]. At that point, the local governments and policy makers try to increase environmental benefits by control of industry for pursuing circular initiatives they do not regard economically advantageous where it is needed to overcome these conflicting situations by top-down and bottom-up approaches with the goal of achieving circular economy [6]. In this case, it is crucial to understand deeply Circular Economy (CE) has a complex philosophy particularly when it comes to cities and related applications. Kirchherr et al. defines Circular Economy as:

“....an economic system that replaces the 'end-of-life' concept with reducing, alternatively reusing, recycling and recovering materials in production/distribution and consumption processes. It operates at the micro level (products, companies, consumers), meso level (ecoindustrial parks) and macro level (city, region, nation and beyond), with the aim to accomplish sustainable development, thus, simultaneously creating environmental quality, economic prosperity and social equity, to the benefit of current and future generations. It is enabled by novel business models and responsible consumers." [7].

Cities have a great potential to provide a framework for designers to understand how to lead sustainable development by reducing environmental footprint caused by design and related disciplines. It can also help decision makers, stakeholders, and consumers to understand where their resources come from and where their waste goes to.

\section{SOCIAL INNOVATION AND SUSTAINABLE DESIGN THINKING}

Social innovation is a wider term with a full range of activities that invent solutions to social problems in a creative as well as positive way [8]. Social innovation includes all sectors like public or private and it is a combination of the logics and social relations conventionally inherent in these sectors [9]. However, according to Hochgerner [10] the concept of innovation was mainly perceived to be the characteristic of economy and technology. Social innovation can be radical depending on the change with regard to existing ways of thinking and it can also be top-down or bottom-up depending on where the challenge starts. In this respect, Manzini [11] states that, design helps people to realize the problems of the production process and to get related with meaningful local activities as consumers linked to the vision. According to him, everyday life innovations create ideas about solving problems in any scale of design and creative communities consider these design-led processes in their bottom-up efforts to find solutions.

Designers as professionals should be involved in these design activities for communities. In this process, designers should work with related actors by bringing them together for sharing ideas and potential solutions. On the other hand, in designing for communities' process, the designer develops solutions after realizing the weaknesses and strengths and social innovation can be identified as the result of various interactions, comprised of bottom-up and top-down processes where hybrid structure is fundamental for sustainable developments.

Heiskala [12] also defines innovation as a new idea that changes social practices to achieve an improvement on social and economic performance, which emphasizes the 
context specific nature of innovation. On the other hand, Howaldt and Schwarz [13] define innovation as an intervention designed to initiate developments on technology, economics, as well as social practices where design has been extended to the contexts for many scales such as cities, objects and cultures, etc. Morelli [14] emphasizes that designers consider their roles to be complementary to business strategies. He also adds the viewpoint of design needs to be changed for addressing the social problems brought by globalization. In this case, there is an urgent need for the exploration of new areas in design, avoiding from the unsustainable practices behind as design professionals [15]. Fuad-Luke [16] also points out the question whether the creation of well-being rather than the goods of services, be a new aim of design.

According to Buchanan [17] to have a pure vision of design thinking, it is necessary to explore divergent meanings of design both in theory and practice where design thinking can help the social enterprises for being innovative, as well. Design thinking also involves stages such as experimenting and redesigning as an analytic and creative process. It is also an interactive process and design activity has an opportunistic nature that is crucial in the process [18]. As stated by Owen [19] design thinking is as important as science thinking with its contributing value to decision-making process.

Creating a human-centred approach to problem solving involves imagining future scenarios [20] that also underlines the role of design thinking for realizing possibilities and defines it as a mindset [21]. It is argued that design thinking is mainly related to the imaginative act of mind by turning a possibility into a reality and meaning of design thinking sometimes goes beyond designer to the whole culture or a society by referring creative inquiry. In this respect, they emphasized that the professional designers' problemsolving abilities are crucial for the firms, societies and for communities that needs innovations and changes in design thinking which is essential for social innovation. In this respect, the education of designers and planners are crucial for developing a successful design model which considers the needs of communities as well as individuals.

Considering city-scale studies, to reach for a successful social innovation understanding the existing barriers and trying to remove them is crucial. Other factor that creates resistance for the development and social innovation is limited access to the finances needed as well as poorly developed networks [22]. In this case, lack of financial resources and related networks, difficulties of adopting an open innovation paradigm can be defined as the main problems for change for social innovation. Fundraising is the main problem for the NGOs that have great ideas that cannot be applied at any scale [23]. Measuring social innovations and public engagement are also vital for the development as well. Citizen engagement is an important component of social innovation which is more than idea, knowing what works is essential for its successful implementation and dissemination. Evaluations are also crucial for social innovation to find out what works [24].

\section{WORKSHOP ON SUSTAINABLE DESIGN THINKING AND CIRCULAR ECONOMY}

The traditional understanding of economic activity is mainly based on a linear model which starts with the raw materials and natural resources for products used by consumers and throw them away as a landfill from personal to city scale. This conventional model does not take into account the environmental, social and economic costs related to each step of the circle including extraction, transformation, usage and disposal of resources, which is unsustainable in the long term. On the other hand, circular economy offers a new and developed model in terms of sustainability where the products, processes and resources are maintained for a long term and aimed for zero waste by using closing the loops process. 
Concerning the cities, this transition towards a circular economy affects various areas such as local policies, mobility, agriculture, waste management, as well as consumer education. It is also crucial for concerning actors from local governments to all other sectors related to city scale.

As stated earlier, circular economy, sustainable design thinking and social innovation are complex contexts with their interdisciplinary and cross scale structures. In this respect, a one-day workshop has been conducted in Izmir University of Economics, Faculty of Fine Arts and Design to bring local decision-makers and designers together to discuss their ideas in order to identify the local obstacles and barriers for future collaborations on circular design starting from the decision-making process to the applications. At the beginning of the workshop, presentations have been made by the representers of local municipality of İzmir on this subject to explain how planning and design decisions and related applications have been made by the local government and stakeholders of the city of İzmir.

As the second step of the workshop, design professors from the university gave brief lectures on sustainable design thinking and how to improve environmental awareness through design. After having lectures on the sustainability and circular design, design students were also joined to the workshop with their ideas, and they were expected to define the correlations between circular economy and sustainable design thinking in the light of the presentations of the local government and design professionals within the boundaries of their professions from various design scales including urban design, architecture, and industrial design. In this respect, they were also expected to develop possible scenarios and to present their ideas for sustainable future.

Through the study they had a chance to conduct interviews with the local government to analyse the current situation in terms of decision-making processes and how can be developed through participatory design principles. After a daily workshop, the findings were remarkable in terms of sustainable design thinking and improving circular economy via applications which have only been considered in a limited way so far by the politics, decision makers and stakeholders. On the other hand, the workshop was also beneficial for design students by increasing their awareness on how to participate those decision-making processes for their cities as designers and future decision makers.

At the end of the workshop, parameters and actors for Circular Design Thinking were defined in several subtitles and some of those subtitles appeared as the main obstacles and difficulties when it comes to circular design thinking approach (Fig. 1).

- In the first section derived from the daily workshop results, which is defined as Technology, the main problem was the lack of feasibility and the weak connection among public services which needs to be strong enough to have a real development for circular design thinking and related applications starting from the local to the whole country.

- Second section of the diagram is entitled as People, which is defined extremely crucial in terms of public awareness and participatory decision-making processes as one of the fundamentals for sustainable development. However, according to the discussions of the workshop local governments agreed on that public awareness must be improved by increasing participatory design studies and public information. In this respect, all participants were agreed that these network among the local governments, designers and stakeholders need to be stronger than ever before for sustainable and long-term results. 


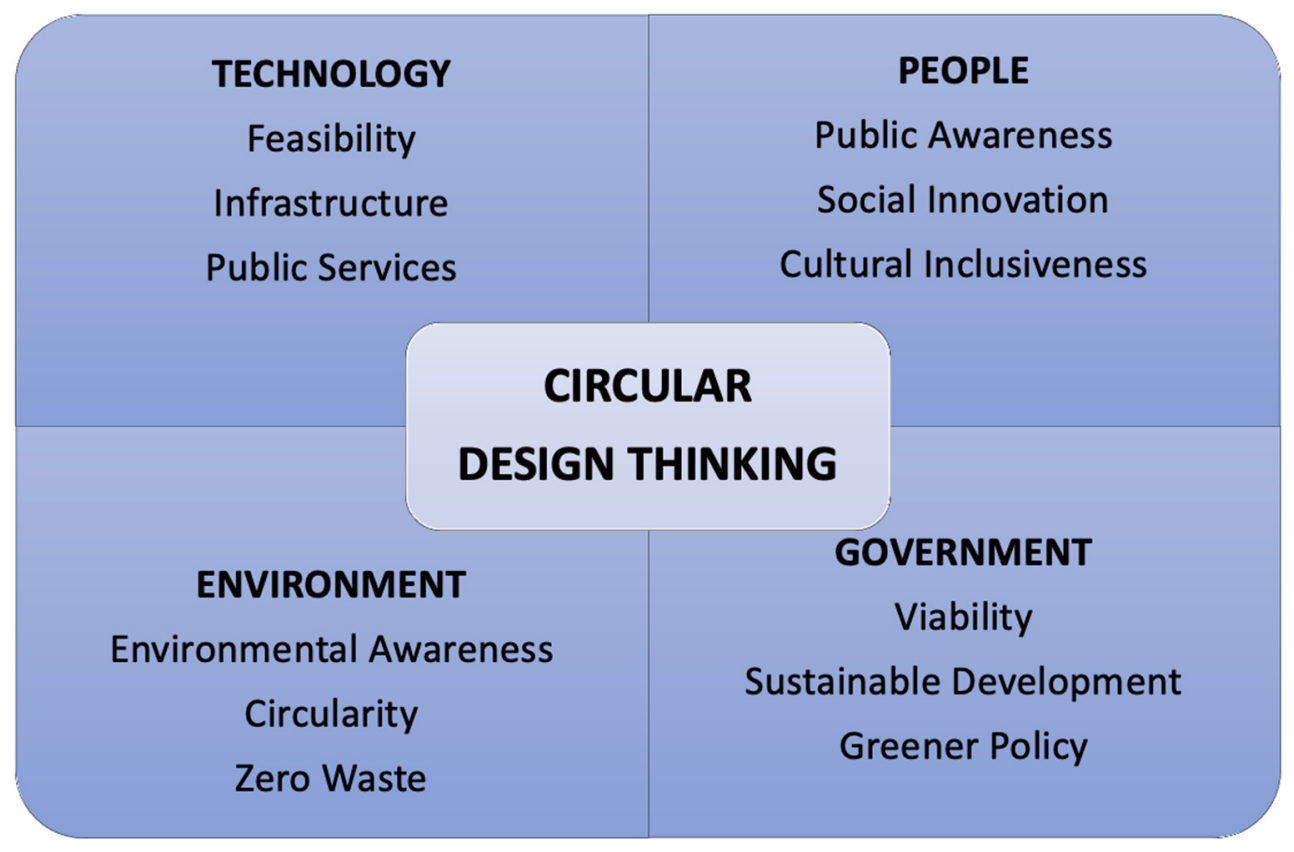

Figure 1: Parameters for circular design thinking.

- Third section was defined as Environment, which is the core component from the viewpoint of sustainability and urgently need developments like improving environmental awareness for all actors in cities which lead to the reach goals like increasing circularity and zero waste for cities. As the final section which refers to circular design thinking.

- Government has a crucial role to play to achieve those goals. However, this workshop has shown that it is not easy to create a greener policy which leads to a sustainable development and viability. In order to reach the goals defined in these subtitles, there must be a strong and ongoing connections among all kind of actors starting from the decision-making process till the application and eventually end of life for any kind of design related ideas which also needs to be supported via circular economy.

Consequently, the results of this particular study have shown that it must be considered that sustainable design thinking and circular economy is not a simple process that any institution can do alone. Because of its complex nature, there are many obstacles and difficulties, and it requires connections among governments, stakeholders, and related sectors. Cities consist of many features such as infrastructure, utilities, and related services in it. Considering this complicated structure of cities, it is way more important for designers to help local governments and decision-makers to understand the possible results and consequences of their policies and actions.

\section{CONCLUSION}

Successful networks among all organizations no matter how it flows from bottom to top (or vice versa) and heterogeneity of actors aiming for social innovations are crucial. However, through the discussions, changing the values defined as the most difficult part for this 
process, although it is much easier to change products and related processes through technical advances. In this respect, sustainable design thinking is a key element to increase awareness and create socially embedded solutions for cities. Designing the capabilities and institutionalizing them will be beneficial for the various organizations as well as individuals to approach new opportunities and possible solutions. Participants of the workshop were also agreed on that there is still a lack of awareness not only for the governmental issues but also for designers where sustainability-based innovations are important for communities in any scale, combining with the collaborations among related actors for design process to turn problems into opportunities and create values.

In this respect, the workshop conducted for this study mainly proved that there is an urgent need for powerful and two-way collaboration (top-down and bottom-up) among the designers, local governments, stakeholders, and related NGOs for the social change and increasing awareness to occur and to diffuse to a community (Fig. 2).

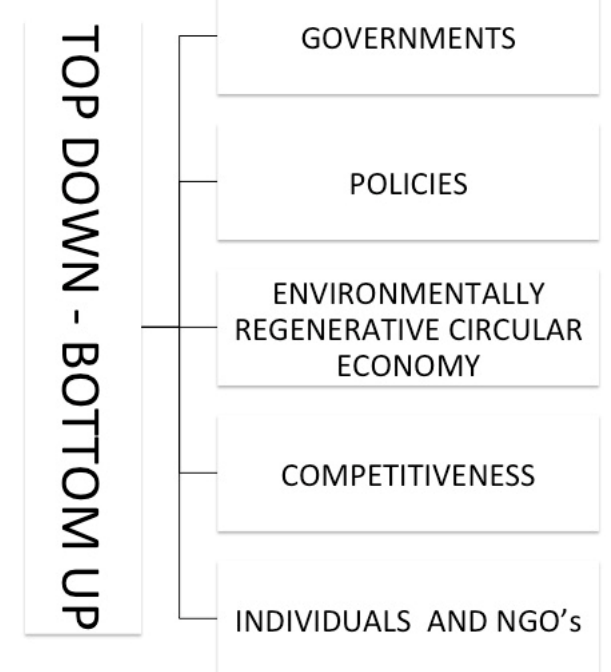

Figure 2: Actors for top-down and bottom-up approaches.

As one of the findings from the workshop, sustainable design thinking and circular economy were defined by the participants as complex contexts of solutions through the viewpoint of sustainability with a systemic perspective built on environmental, economic, and social dimensions and mainly should aim to design out waste to keep natural values in the cycle for resource security and efficiency in any scale, from local to the whole city as in the pyramids below (Fig. 3).

Consequently, circular design concept should spread all over the world in collaboration with the circular economy which aims to redesign everything including cities, products, business models, etc. In this case, although technology is one of the biggest influencers that allows to create new ways of thinking to reach to a smart and sustainable city where the natural resources used wisely in each step, increasing environmental awareness for developing participatory design process is also crucial for any long term and sustainable 


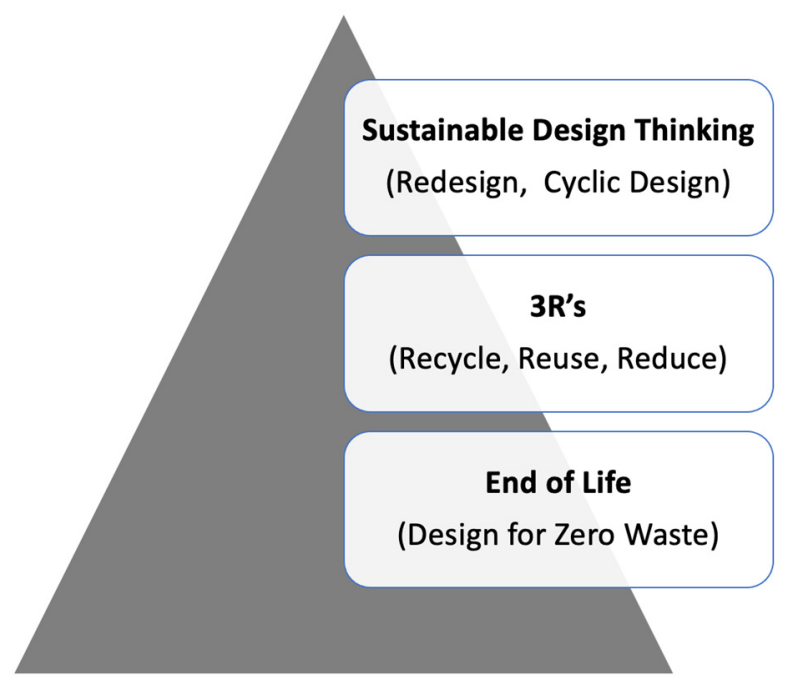

Figure 3: Pyramids of sustainability for cities.

solutions. Having a circular vision, by defining circular strategies and applying those circular principles in city functions are crucial to create a good framework for the circular transition of cities. To sustain this system among the whole city administrations it is also important to build circular awareness and promote a culture of collaboration among all actors to have a sustainable development.

\section{REFERENCES}

[1] Ghisellini, P., Cialani, C. \& Ulgiati, S., A review on circular economy: The expected transition to a balanced interplay of environmental and economic systems. Journal of Cleaner Production, 114, pp. 11-32, 2016.

[2] Bocken, N.M.P., de Pauw, I., Bakker, C. \& van der Grinten, B., Product design and business model strategies for a circular economy. Journal of Industrial and Production Engineering, 33(5), pp. 308-320, 2016.

[3] Ellen MacArthur Foundation (EMF), Towards the circular economy. Economic and Business Rationale for an Accelerated Transition, 2012.

[4] Prendeville, S., Cherim, E. \& Bocken, N., Circular cities: Mapping six cities in transition. Environmental Innovation and Societal Transitions, 26, pp. 171-194, 2018.

[5] Brunner, P.H., Urban mining a contribution to reindustrializing the city. Journal of Industrial Ecology, 15(3), pp. 339-341, 2011.

[6] Lieder, M. \& Rashid, A., Towards circular economy implementation: A comprehensive review in context of manufacturing industry. Journal of Cleaner Production, 115, pp. 36-51, 2016.

[7] Kirchherr, J., Reike, D. \& Hekkert, M., Conceptualising the circular economy: An analysis of 114 definitions. Resources, Conservation \& Recycling, 127, pp. 221-232, 2017.

[8] Huysentruyt, M., Bulakowskiy, M. \& Ramsden, P., Guide to social innovation. European Commission, DG Regional and Urban Policy and DG Employment, Social Affairs and Inclusion, 2013. 
[9] Nicholls, A. \& Murdock, A., The nature of social innovation. Social Innovation: Blurring Boundaries to Reconfigure Markets, eds A. Nicholls \& A. Murdock, Palgrave MacMillan: London, 2012.

[10] Hochgerner, J., The analysis of social innovations as social practice, zentrum fur soziale innovation 2011.

https://www.zsi.at/attach/The\%20Analysis\%20of\%20Social\%20Innovations\%20as\% 20Social\%20Practice.pdf.

[11] Manzini, E., Making things happen: Social innovation and design. Design Issues, 30(1), pp. 57-66, 2014.

[12] Heiskala, R., Social innovations: Structural and power perspectives. Social Innovations, Institutional Change and Economic Performance: Making Sense of Structural Adjustment Processes in Industrial Sectors, Regions and Societies, eds T.J. Hamalainen \& R. Heiskala, Edward Elgar: Cheltenham, pp. 52-79, 2007.

[13] Howaldt, J. \& Schwarz, M., Social Innovation: Concepts, Research Fields and International Trends, Sozialforschungsstelle Dortmund: Dortmund, 2010.

[14] Morelli, N., Social innovation and new industrial contexts: Can designers "industrialize" socially responsible solutions? Design Issues, 23(4), pp. 3-21, 2007.

[15] Chick, A. Design for social innovation: Emerging principles and approaches. Iridescent, 2(1), pp. 78-90, 2012. DOI: 10.1080/19235003.2012.11428505.

[16] Fuad-Luke, A., Design Activism: Beautiful Strangeness for a Sustainable World, Earthscan: London, 2009.

[17] Buchanan, R., Worlds in the making: Design, management, and the reform of organizational culture. She Ji: The Journal of Design, Economics, and Innovation, 1(1), pp. 5-21, 2016.

[18] Razzouk, R. \& Shute, V., What is design thinking and why is it important? Review of Educational Research, 82(3), pp. 330-348, 2012.

[19] Owen, C., Design thinking: Notes on its nature and use. Design Research, Quarterly, 2(1), pp. 16-27, 2007.

[20] Kimbell, L., Rethinking design thinking: Part I. Design and Culture, 3(3), pp. 285306, 2011.

[21] Docherty, C., Perspectives on design thinking for social innovation. Design Journal, 20(6), pp. 719-724, 2017.

[22] Nusem, E., Wrigley, C. \& Matthews, J.H., Developing design capability in nonprofit organizations. Design Issues, 33(1), pp. 61-75, 2017.

[23] Planing, P., Business model innovation in a circular economy. Reasons for nonacceptance of circular business models. Open Journal of Business Model Innovation, 2015.

[24] Phills, J.A., Deiglmeier, K. \& Miller, D.T., Rediscovering social innovation. Stanford Social Innovation Review, Fall, pp. 34-43, 2008. 